\title{
EL DERECHO INTERNACIONAL ANTE LOS DESAFÍOS \\ DEL GENOMA HUMANO Y LA BIOÉTICA, EN EL MARCO \\ DE LA ORGANIZACIÓN Y LAS DECLARACIONES \\ INTERNACIONALES. SU PROYECCIÓN AL DERECHO \\ MEXICANO
}

\author{
Juan Carlos VeLÁzQUEZ ELIZARRARÁS*
}

\begin{abstract}
RESUMEN: El derecho internacional y los derechos humanos, así como los sistemas jurídicos internos de los Estados, tienen en el genoma humano y la bioética, dos de los más grandes desafíos de los tiempos modernos, a los cuales vienen dando diferentes respuestas y un consistente, aunque no suficiente, tratamiento político-normativo y legislativo, con el apoyo de organismos intergubernamentales, el concurso activo de la sociedad civil internacional y la utilización sistemática de la metodología jurídica de las declaraciones internacionales, junto con los instrumentos convencionales concertados a nivel regional.
\end{abstract}

ABSTRACT: The human genome and the bioethics are two of the greatest modern challenges to the international law, the human rights and the internal juridical systems of the States. Different answers and a consistent but not sufficient political-normative and legislative treatment have been given to these problems with the support of intergovernmental organizations, the active participation of the international society and the systematic use of the juridical methodology of the international declarations in conjunction with the conventional instruments use in a regional level.

RÉSUMÉ: Le droit international et les droits humains de la même manière que les systèmes juridiques internes des États ont dans le génome humain et la bioéthique, deux des plus grands défis dés modern temps. Différent réponses et un consistent mais pas suffi traitement politique normative et législative a était donné avec le support des intergouvernementaux organisations, la participation active de la société civil international et la utilisation systématique de la méthodologie juridique des déclarations internationales, en conjonction avec les instruments conventionnels occupées dan l'étage régional.

* Doctor en ciencias políticas y sociales, y en relaciones internacionales, y profesor en la Facultad de Ciencias Políticas y Sociales, y en el Posgrado de la Facultad de Derecho de la UNAM, así como en la Universidad Anáhuac del Sur. Investigador nacional. 
SUMARIO: I. Introducción. II. Precisión conceptual del genoma humano. III. Desarrollo del genoma humano en el marco de las organizaciones y las declaraciones intergubernamentales. IV. El genoma humano en el ámbito de las organizaciones no gubernamentales y las declaraciones internacionales. V. Evolución del ordenamiento jurídico del genoma humano en México y el papel de las instituciones internas e internacionales.

VI. Reflexiones finales.

\section{INTRODUCCIÓN}

A principios de la década de los años noventa del siglo pasado se inició el denominado Proyecto Genoma Humano (XE "Proyecto Genoma Humano") PGH (XE "PGH"), que tenía como objetivo principal determinar cuántos y qué tipo de genes (XE "genes") conforman el organismo del ser humano, y a partir del cual empezarían a surgir serios debates en torno a su impacto en la vida individual y colectiva de las personas. Después de más de tres lustros del inicio formal del PGH (XE "PGH") y a pesar de su amplia difusión a través de los medios de comunicación masiva, no se ha logrado entender con exactitud a qué se refiere exactamente cada una de las acepciones y términos adoptados. Así pues, el imaginario colectivo y el sentido social común continúan peligrosamente confundidos.

Como estudiosos del derecho internacional, la motivación del presente artículo responde al hecho de que para la mayoría de las personas físicas y de las entidades morales y sociales, todavía se mantiene por lo general en terrenos de lo ignoto cualquier aspecto relativo al régimen jurídico aplicable al genoma humano, a los derechos y obligaciones que la nueva temática les reserva, a la naturaleza jurídica que caracteriza al fenómeno, o bien al papel que deben jugar las instituciones al interior y exterior de las soberanías estatales y el rol de la sociedad civil internacional, así como el criterio y conocimiento con que el legislador enfrenta el nuevo reto.

Para abordar y responder a estas y otras inquietudes hemos planteado la siguiente hipótesis central de trabajo: El desarrollo del derecho internacional contemporáneo, y su capacidad de respuesta ante los desafíos que le presentan la regulación del genoma humano y la bioética, se han cimentado esencialmente, en detrimento de otros recursos de las relacio- 
nes internacionales, en el marco jurídico-político institucional de las organizaciones internacionales gubernamentales y no gubernamentales y en la técnica de la negociación-pronunciamiento que ofrecen las declaraciones internacionales, las cuales al no tener el carácter estrictamente vinculante que caracteriza a los instrumentos convencionales como los tratados, han entorpecido su recepción pronta, eficaz y uniforme en los órdenes jurídicos internos de los Estados como el mexicano, y por consiguiente las legislaciones nacionales asumen criterios discrecionales que las distancian muchas veces de las líneas rectoras consensuadas y consentidas por la vía consuetudinaria que representan los actos declarativos multilaterales.

Esto no significa que los recursos de las organizaciones y las declaraciones internacionales hayan sido o sean inapropiados o inconvenientes, nada por el estilo, simplemente han devenido insuficientes para lograr un orden normativo nacional e internacional del genoma humano más acabado, aplicable y completo; de hecho, la comunidad internacional no ha sido capaz de desarrollar vías alternativas o ha carecido del conocimiento y la voluntad política necesarios para arribar a una correcta toma de decisiones políticas y jurídicas para resolver problemas complejos. De momento, no contamos con otras herramientas para abordar jurídicamente el dilema planteado que no sean las institucionales y las declaraciones internacionales.

\section{PRECISIÓN CONCEPTUAL DEL GENOMA HUMANO}

\section{Elaborando una definición técnica}

Actualmente hay muchas definiciones de lo que significa "genoma humano", la mayoría de ellas coinciden en sus propuestas. Para el politólogo Hernández-Vela, se le define como "el conjunto de todos los genes de los 23 pares de cromosomas que tiene el núcleo de las células de cada persona y que contiene todos sus caracteres genéticos y su patrimonio hereditario". ${ }^{1}$ Para Matt Ridley "el genoma humano es todo el conjunto de genes que viene empaquetado en veintitrés pares de cromosomas dis-

1 Hernández-Vela, Edmundo, Diccionario de política internacional, 5a. ed., México, Porrúa, 1999, p. 362. 
tintos". ${ }^{2}$ Sin embargo, visto de esta forma es difícil entender la magnitud de lo que realmente es el genoma humano. Tal como se mencionó, éste se halla conformado por 23 pares de cromosomas que significa "cuerpo coloreado", donde cada cromosoma es una larga cadena de la sustancia química ácido desoxirribonucleico, conocido simplemente como ADN. A lo largo de esta molécula larga y no ramificada de ADN están unidos grupos de proteínas similares a cuentas denominados hitotas. ${ }^{3}$ Walter Flemming fue el primero en ver cromosomas humanos en 1879 , y en 1888 Wilhelm Van Waldeyer los llamaría "cromosomas". El ADN está compuesto de cuatro clases de "nucleótidos", cada nucleótido tiene adenina (A), guanina $(\mathrm{G})$, citosina $(\mathrm{C})$ o timina $(\mathrm{T})$, un grupo de fosfatos, azúcar desoxirribosa y una base que contiene nitrógeno; la diferencia entre los cuatro tipos de nucleótidos reside en las bases nitrogenadas que son las que codifican el proceso de la fabricación de proteínas. ${ }^{4}$

\section{Elaborando una definición jurídica}

En el ámbito internacional hay diversas instituciones que han propuesto algunas definiciones sobre el genoma humano desde una perspectiva jurídica. La Declaración del Genoma Humano y los Derechos Humanos de 1997 de la UNESCO —el instrumento internacional que aborda de manera global el tema del genoma humano- propone su definición en el artículo 1o. que señala: "el genoma humano es la base de la unidad fundamental de todos los miembros de la familia humana y del reconocimiento de su dignidad intrínseca y su diversidad. En sentido

2 Ridley, Matt, Genoma. La autobiografía de una especie, trad. de Irene Cifuentes, México, Taurus, 2002, p. 15.

3 Lee, Thomas F., El Proyecto Genoma Humano. Rompiendo el código genético de la vida, 2a. ed., trad. de José A. Álvarez, Barcelona, Gedisa, 1991, pp. 12 y 13.

4 Compendiando las definiciones antes mencionadas, se puede decir llanamente que el genoma humano es el conjunto de todos los genes que conforman el cuerpo humano, sin embargo, cuando se finalizó formalmente el mapa genético, se concluyó que sólo el $1 \%$ de nuestros genes conforman la totalidad del genoma, es preciso por tanto no confundir la totalidad de los genes con el genoma, pues éste no sólo se conforma de genes, sino de otras sustancias, muchas de ellas con un funcionamiento todavía desconocido, es decir, que el genoma humano se refiere a la totalidad del material que conforman a los cromosomas, es por ello que desde esta perspectiva sea cuestionable la definición conocida de "genoma humano". 
simbólico, el genoma humano es el patrimonio de la humanidad". ${ }^{5}$ Hay otras definiciones que más adelante conviene retomar. Sin embargo, la definición proporcionada por la Declaración de la UNESCO plantea algunos problemas al señalar el valor simbólico del genoma humano, creando ciertas imprecisiones.

En nuestra opinión y sin pretender arribar a una definición del genoma humano apegada estrictamente a derecho, dado que se trata de un concepto dinámico e inacabado, éste debe ser considerado jurídicamente como la unidad de todos los seres humanos, y el reconocimiento de su dignidad intrínseca, misma que es fundamento real e insustituible de los derechos humanos internacionalmente aceptados (XE "derechos humanos"). Es el conjunto de los genes que constituyen el individuo humano y que son comunes a toda la especie humana, cuya protección legal corresponde al derecho y su correcta utilización es materia propia de los derechos humanos fundamentales. Los derechos de protección al genoma humano son iguales e inalienables para todos los miembros de la familia humana teniendo en consideración la evolución de las ciencias de la vida y los problemas éticos que plantean las aplicaciones de éstas en el ser humano, sus derechos y libertades esenciales.

La ciencia jurídica debe garantizar pues, que los progresos de la ciencia y la tecnología beneficien a las personas sin atentar contra sus derechos, garantizando el respeto de su integridad y del principio del conocimiento libre e informado basado en la evaluación de riesgos.

\section{DESARROLLO DEL GENOMA HUMANO EN EL MARCO DE LAS ORGANIZACIONES Y LAS DECLARACIONES INTERGUBERNAMENTALES}

A partir de la década de los noventa varias organizaciones intergubernamentales, principalmente las integradas en el sistema de las Naciones Unidas, pusieron especial atención en las consecuencias que tendría el avance biotecnológico del Proyecto Genoma Humano, vislumbrando las posibilidades de ciertas transgresiones a los derechos humanos. Tal preocupación se ve reflejada en la elaboración de una serie de estudios,

5 UNESCO, Declaración Universal del Genoma Humano y los Derechos Humanos, 11 de noviembre de 1997. 
reuniones y debates así como el pronunciamiento de importantes iniciativas en torno al tema genómico con la finalidad de plantear soluciones sociales, éticas y legales mediante la emisión de documentos, resoluciones, declaraciones y convenios internacionales enmarcados en el derecho internacional y los derechos humanos como lo apreciaremos a continuación.

\section{El genoma humano en las acciones sustantivas de la UNESCO}

La UNESCO fue el primer organismo especializado de las Naciones Unidas en preocuparse y dar respuesta a los problemas que plantea el saber científico. Con los rápidos avances dentro del campo de las ciencias biológicas la organización tomó conciencia de la necesidad de celebrar reuniones oportunas para implementar planes con el fin de concentrar los esfuerzos en los retos globales más importantes en los campos de competencia de la organización y enfocarse en planes de acción para el futuro. Uno de esos desafíos fue el estudio sobre el genoma humano, el cual representa la cúspide del conocimiento íntimo de la biología humana. Con la puesta en marcha del PGH, la organización buscó soluciones ante los problemas que implicaría el uso de la información genética en el campo de los derechos humanos y tratando de resolver los dilemas éticos, sociales y jurídicos del mismo. ${ }^{6}$

Además del claro mandato de la organización, el impulso de la protección del genoma humano, y la necesidad del análisis de su impacto en los derechos humanos y motivó que su labor se diera en los niveles de coordinación de los esfuerzos de investigación internacional, participación de los países subdesarrollados, y la estimulación de los debates desde todas las perspectivas del conocimiento del PGH. La UNESCO jugó un papel fundamental cuando el PGH era rechazado por grupos opuestos a los fines de éste y pocos vislumbraban su alcance. Así, copatrocinó el Primer Encuentro de Cooperación Internacional para el Proyecto Genoma Humano que se realizó en Valencia en octubre de 1988. En este encuentro y sus sucesivas reuniones se impulsó a la organización del Comi-

6 Aufray, Charles, El genoma humano, trad. de Eliane Cazenave-Tapie, México, Siglo XXI Editores, 2004. 
té de Coordinación Científica de la UNESCO en 1989 y la adopción de la Declaración de Valencia sobre el Genoma Humano en 1990. ${ }^{7}$

Uno de los objetivos principales de la declaración fue la de exaltar la dignidad humana como elemento supremo para lograr el bienestar y la justicia del individuo y la lucha contra la discriminación genética, reconociendo la diversidad y complejidad humana. Introduce el principio de intimidad genética, que es aquél que protege la información derivada del genoma de cada persona como una máxima fundamental para la protección de los derechos humanos de cada individuo. También reafirma el principio del consentimiento libre e informado para toda investigación que implique la obtención de información genética, así pues, de acuerdo con el documento, únicamente se podrá llevar a cabo un diagnóstico genético con la autorización del individuo o del representante legal, previa información sobre los beneficios y consecuencias del mismo.

El Comité Internacional de Bioética (CIB, 1993) creó una comisión jurídica compuesta por juristas a la que se le encomendó la formulación de propuestas para dar forma y contenido al instrumento internacional de protección del genoma humano. Durante la primera reunión de la comisión el 7 de abril de 1994 propuso la metodología para la elaboración del instrumento internacional basándose en la elaboración de convenciones, declaraciones concernientes a los derechos humanos. La fórmula declarativa había sido la más usada al finalizar la Segunda Guerra Mundial como un recurso del derecho internacional para crear conciencia en garantizar el bienestar de la humanidad a través de la observancia de los derechos humanos. ${ }^{8}$ A pesar de crear conciencia moral, las declaraciones fueron reconocidas tanto en teoría como en la práctica con fuerza legal, y un claro ejemplo es la Declaración Universal de los Derechos Humanos cuyas disposiciones han sido introducidas en las legislaciones nacionales de numerosos países. Un instrumento declarativo podría ser lo suficientemente general, manteniendo cierta flexibilidad en un tema científico en constante avance como el genoma humano, además de considerar las posiciones que obedecen a las diferencias culturales, politicas e incluso religiosas de cada país.

7 Brena Sesma, Ingrid (coord.), Células troncales. Aspectos científicos-filosóficos y jurídicos, México, UNAM, Instituto de Investigaciones Jurídicas, 2005.

8 Beyer Ruiz, María Emilia, Gen o no gen. El dilema del conocimiento genético, México, Lectorum, 2002. 
La convención podía ser un complemento de la declaración estableciendo más precisamente la responsabilidad de los Estados, las organizaciones internacionales, e incluso a los individuos creando la obligatoriedad de su aplicación para los firmantes. Ciertamente, este hecho daba a la fórmula convencional algunos puntos en contra, a saber, en la práctica la adopción y sucesiva aplicación de una convención podría lograrse en muchos años, baste recordar el Pacto de Derechos Civiles y Políticos adoptado en 1966 y puesto en vigor hasta 1976, casi 10 años después. En una materia tan cambiante y dinámica en donde todos los días hay algún avance como el demostrado a raíz del inicio del PGH, se consideró que el factor tiempo era de especial importancia ya que su progreso era inevitable y el mundo necesitaba cuanto antes de la regulación internacional de la materia para proteger de esta manera la especie humana y sus derechos. De acuerdo con esta premisa se consideró que una convención era rígida considerando que habría que hacer numerosas enmiendas al instrumento pasados algunos años y éstas requerirían de la aprobación de los Estados miembros. Había otra opción, la de preparar tanto una convención como una declaración con el fin de que esta última adquiriera eficacia.

Ante estas tres opciones, había que analizar las diferentes soluciones legales que ofrecía el derecho internacional, por lo que la Comisión Jurídica del CIB propuso las siguientes:

a) Adoptar sólo la declaración: ésta debía de considerar como ejemplo a la Declaración sobre los Principios del Derecho Internacional Concerniente a las Relaciones Amistosas y Cooperación entre los Estados de acuerdo con la Carta de las Naciones Unidas.

b) Adoptar una declaración y una convención, que tendrían que prepararse simultáneamente, considerando que el proyecto de convención llevaría mucho más tiempo.

c) Adoptar sólo una convención, dada la obligatoriedad que ésta representa a pesar del factor tiempo y las complicaciones que su aprobación requiere.

d) Utilizar el método o propuesta de la OIT cuyo mecanismo de firma garantiza la ratificación expedita de los Estados miembros, la cual se hace dentro de los 18 meses siguientes a la adopción de la convención y cada Estado firmante tiene la obligación moral de proporcionar un informe relativo al progreso de la ratificación en cada país. 
e) La elaboración de una ley modelo que armonice el derecho. Esta técnica jurídica introduce normas uniformes a la diversidad de legislaciones de los Estados, con la finalidad de asegurar la coordinación y cumplimiento de los objetivos del instrumento internacional; al mismo tiempo mantiene cierta flexibilidad para que cada Estado soberano de acuerdo con su Constitución adopte las disposiciones más adecuadas a su legislación.

La revisión de estas propuestas permitió determinar que la declaración sería la fórmula más acertada para lograr los propósitos del futuro instrumento internacional y para obtener la adhesión de la comunidad internacional a los principios encaminados a fomentar la protección del genoma humano, amén de que tenía la posibilidad de ser adoptada con mayor rapidez. El instrumento debería constituir un recurso de principios de interpretación de las autoridades nacionales de acuerdo con la propia normativa de cada país. Y fue también cuando se determinó que la protección del genoma humano debería basarse en los derechos humanos, especialmente en el respeto de las libertades fundamentales y la no discriminación.

La declaración debía contener un número relevante de principios fundamentales como el respeto de la dignidad de la persona humana, el consentimiento, no comercialización del cuerpo humano y sus componentes, la investigación científica o la herencia común de la humanidad que sirviera como una guía de principios para la legislación nacional. No obstante la opción de la fórmula declaratoria no excluía la posibilidad de concretar una futura convención como un complemento que posteriormente precisaría la responsabilidad de los Estados, de las organizaciones internacionales e incluso los individuos. En esencia, quedaba claro que "la doctrina de las Naciones Unidas considera que una declaración es un instrumento formal y solemne, que se justifica en escasas oportunidades cuando se enuncian principios de gran importancia y de valor duradero, haciéndose hincapié en la autoridad moral".

\section{A. La Declaración Universal del Genoma Humano y los Derechos} Humanos de 1997

Se trata del instrumento más importante relativo al tema dentro del Sistema de Naciones Unidas, incluso a nivel internacional. Es un documento innovador que trasladó conceptos científicos a conceptos legales 
que el mismo derecho aún no había aprehendido hasta ese momento. La necesidad de la comunidad internacional de adoptar un documento relativo al genoma humano, surge de la conciencia de un vacío legislativo en el ámbito internacional que protegiera al genoma humano e hiciera el llamado para ser legislado en el ámbito nacional en aquéllos países que no poseyeran disposiciones al respecto; de esta manera, las normas emanadas del instrumento internacional servirían como fuente de derecho armonizando los sistemas jurídicos nacionales en materia bioética y relativa al genoma humano y tal adopción impediría las prácticas divergentes en tales ámbitos. Así pues, después de la presentación de numerosos proyectos el 11 de noviembre de 1997 se aprobó esta Declaración que se compone de siete capítulos titulados: la dignidad humana y el genoma humano; el derecho de las personas interesadas; investigaciones sobre el genoma humano; condiciones de ejercicio de la actividad científica; solidaridad y cooperación internacional; fomento de los principios de la declaración; y aplicación de la misma. ${ }^{9}$

Propone una definición desde la visión filosófico-jurídica que indica que el genoma humano es la base de la unidad fundamental de todos los miembros de la familia humana y del reconocimiento de su dignidad intrínseca y su diversidad. Enfatiza que las investigaciones desarrolladas en torno al genoma humano atañen a la humanidad, a la especie, como conjunto de individuos a los que podría afectar el desarrollo de la genética humana; esto es, que el genoma humano es en sentido simbólico patrimonio común de la humanidad. La noción de patrimonio común de la humanidad hace hincapié en la exigencia de un aprovechamiento compartido equitativo de los conocimientos científicos sobre el genoma humano, que han de redundar en beneficio del conjunto de la humanidad. No obstante, este principio no excluye que los resultados de la investigación genética puedan ser objeto de derechos de propiedad intelectual, la protección jurídica de sus resultados no parece que deba descartarse por principio. No se puede decir que el genoma de cada persona depende de un régimen de propiedad colectiva, por lo que de acuerdo con la declara-

9 Algunos de los problemas a los que se enfrentó la definición del instrumento es que algunos consideraron que debía ser titulada como "internacional" y no "universal". La respuesta para definir cuál término era el más apropiado fue resuelta gracias a la evaluación de los propósitos que perseguía el mismo, así que en aras de la protección del genoma y de la especie humana sería mejor el uso del término "universal" como el más apropiado. 
ción cada individuo tiene derecho al respeto de su dignidad y derechos independientemente de sus características genéticas, y esa dignidad impide que se reduzca a los individuos a sus características genéticas y se respete el carácter único de cada uno y su diversidad. ${ }^{10}$

Como parte de la prohibición de la determinación genética, la declaración manifiesta que el genoma humano es por naturaleza evolutivo y está sometido a mutaciones expresadas en distintos modos en función del entorno natural y social de cada persona que comprende su estado de salud individual, condiciones de vida, alimentación y educación. Establece diversos principios como el del consentimiento que es consecuencia del derecho a la libertad individual; el derecho de la persona a decidir si se le informa o no de los resultados de los exámenes genéticos y consecuencias (derecho a no saber); la no discriminación a ninguna persona con base en sus características genéticas; el principio de confidencialidad vinculado al respeto de la vida privada; la protección de los derechos humanos y las libertades fundamentales, a través de leyes nacionales y a reserva del estricto respeto del derecho internacional y de los derechos humanos.

Como parte de la defensa de los derechos humanos y lo relativo a las investigaciones sobre el genoma se estableció que toda persona debe tener acceso a los progresos de la biología, genética y medicina en materia de genoma humano, disposición ésta que deriva de otros instrumentos in-

10 El concepto de patrimonio común fue introducido por el derecho internacional para designar bienes que presentan un interés universal, y que la comunidad internacional, por tanto, debe preservar en interés no sólo de las generaciones presentes, sino de las futuras. Para Gros Espiell "la idea de patrimonio común en el derecho internacional tiene un sentido más amplio, distinto y un contenido mucho más vasto y complejo que el concepto de derecho civil, caracterizado por una idea económica... en el derecho internacional, este concepto ha evolucionado, cambiado, y se ha enriquecido, incluyendo otros elementos, se ha transformado en algo distinto". Vila-Coro, María, "La protección del genoma humano", Cuadernos de Bioética, Santiago, vol. IX, núm.. 34, abril-junio de 1998, p. 409. Trasladar la doctrina del patrimonio común de la humanidad al ámbito del PGH conlleva las siguientes determinaciones: a) ningún país o empresa privada de un país podría apropiarse del genoma; b) todos los Estados compartirían la responsabilidad de establecer reglamentos y normas sobre los usos permisibles del genoma; c) todos los Estados tendrían parte en los beneficios derivados del PGH, lo que implica que las secuencias genéticas se pondrían a disposición del público; d) el genoma humano estaría reservado exclusivamente para fines pacíficos; y, e) la comunidad internacional tendría la responsabilidad común de conservar el genoma intacto para las generaciones futuras. 
ternacionales relativos a los derechos humanos; ${ }^{11}$ y con base en el principio de beneficencia las investigaciones relativas al genoma humano deben tender al beneficio de las personas. Ahora bien, como parte de la vigilancia para que se cumplan las condiciones del ejercicio de la actividad científica, se plantea que los Estados reconocerán el interés de promover, en los distintos niveles apropiados, la creación de comités de ética independientes, pluridisciplinarios y pluralistas encargados de apreciar las cuestiones éticas, jurídicas y sociales planteadas por las investigaciones sobre el genoma humano y sus aplicaciones.

En esta misma tónica, se busca crear a nivel internacional las condiciones de un debate en el ámbito de la genética humana, pues la discusión internacional es necesaria para adquirir conciencia y tomar los decisiones; sólo mediante la cooperación se logrará establecer principios y opiniones similares sobre las complejas cuestiones que maneja la bioética. ${ }^{12}$ Esta declaración universal es el instrumento de obligada referencia al debate más complejo que suscita la revolución genética y sus aspectos éticos al ser completamente dedicado a un tema tan novedoso como el genoma humano, pero los progresos en la investigación genética y genómica siguen avanzando, abriendo con ello posibilidades de aplicaciones

11 Baste señalar el artículo 27 de la Declaración Universal de los Derechos Humanos de 1948, y el artículo 15 del Pacto Internacional de Derechos Económicos, Sociales y Culturales de 1966.

12 El último capítulo de la declaración se refiere a su aplicación, y por ser un documento declarativo, no obliga a los Estados a respetar sus disposiciones, sin embargo, establece que éstos intentarán garantizar el respeto de los principios enunciados y la aplicación de los mismos, y deberán también favorecer los intercambios y redes entre comités de ética independientes. Para que la declaración tuviera un impacto real era necesaria la creación de un mecanismo de supervisión que vigilara la aplicación de sus disposiciones. Con fundamento en la Constitución de UNESCO, se prevé que haya convenciones, declaraciones y recomendaciones, pero no un órgano de supervisión para el seguimiento de una declaración. Aun así, por su instauración y el procedimiento que seguiría, estaría basado en la presentación de informes referentes a la aplicación del instrumento, de tal manera que no trasgrediera las normas y principios de derecho internacional. El sistema de supervisión se refiere a la dación de un marco para la aplicación de la declaración hecha por los Estados miembros como un factor fundamental para la adopción de los principios enunciados en la misma en la legislación nacional. Finalmente, el Comité Internacional de Bioética (CIB), establecido en 1993, se erigió como el mecanismo de supervisión de la declaración, y quedó integrado por 36 miembros independientes, designados por el director general. Mediante resolución se aprobaron en 1998 los Estatutos que lo conforman. 
no previstas y planteando problemas éticos nuevos, uno de ellos es el uso de datos genéticos. Consciente de ello, la UNESCO dio un paso más marcando la pauta para la creación de un instrumento que regulara este aspecto encargado al CIB, quien continuaría desempeñando su papel de vigilante ético internacional y consolidaría la autoridad moral que le confirió en su momento, la comunidad internacional y la aprobación de la declaración.

\section{B. La Declaración Internacional de los Datos Genéticos Humanos de 2003}

Vislumbrando que pese a la existencia de declaraciones, directrices y códigos internacionales y previendo el rápido avance de la genética y la constitución de bancos de datos genéticos y el uso de esa información con fines no médicos y reprochables desde la perspectiva ética, la proliferación de bancos de datos genéticos y la tendencia de países que pretenden efectuar censos genéticos ${ }^{13}$ a toda su población, en 2002 se propuso emprender oficialmente la elaboración de un instrumento internacional sobre los datos genéticos. El nuevo documento no abordaría cuestiones éticas de amplio alcance que ya trata la declaración universal, sino que sería una prolongación de esta última y se centraría en cuestiones específicas acerca de la recolección, procesamiento, almacenamiento y utilización de los datos genéticos, situación que planteaba un tema central de debate internacional. ${ }^{14}$

De acuerdo con esta complejidad, la preocupación de los países, de la comunidad científica internacional y la sociedad civil y la urgente necesidad de definir los principios y normas en esta materia, la Declaración Internacional de los Datos Genéticos Humanos fue aprobada y adoptada en la 32a. sesión en la Conferencia General de la UNESCO el 16 de octubre de 2003, misma que cuenta con un preámbulo, 27 artículos distribuidos en seis secciones sobre las disposiciones de carácter general, recolección, tratamiento, utilización, conservación y promoción de los datos y la aplicación de la Declaración.

13 Como ejemplos de estos países tenemos a Islandia y Estonia.

14 Varsi, Rospigliosi, Derecho y manipulación genética, Lima, Fondo de Desarrollo Editorial, 1997. 
El título se refiere a los datos genéticos humanos, sin embargo, la declaración se aplica a la información que se obtenga a partir de muestras; haciendo esta aclaración desde que se inició el trabajo de la declaración, el CIB se enfrentó el problema de definir los "datos genéticos" y señalar las tenues diferencias entre "información y muestras genéticas". ${ }^{15}$ Algunas de sus disposiciones reafirman algunos de los principios y estipulaciones de la declaración universal (como el respeto de la dignidad humana y la protección de los derechos humanos, individualidad, no discriminación, consentimiento libre e informado, derecho pleno a decidir ser o no informado, privacidad y confidencialidad de los datos, responsabilidad de las personas y entidades que tratan datos genéticos humanos y cooperación internacional).

La declaración se basa fundamentalmente en dos principios, la libertad de investigación y la protección de la intimidad como parte del respeto de los derechos humanos, sin embargo, mucho se cuestionó sobre la aplicación de tales disposiciones en tópicos de medicina forense y justicia civil o penal, pues se podría plantear el problema de una eventual incompatibilidad con disposiciones legislativas nacionales, incluso este supuesto se podría plantear como extensivo del artículo 9o. de la declaración de 1997 como "razones imperiosas", así que se decidió hacerlo patente y la única excepción de aplicación de las disposiciones serían cuando se trate de la investigación, el descubrimiento y el enjuiciamiento de delitos penales o de pruebas de determinación de parentesco (medicina forense, procedimientos civiles o penales), que estarán sujetos a la legislación interna que sea compatible con el derecho internacional de los derechos humanos. ${ }^{16}$

A nuestro modo de ver, la de 2003 es una declaración novedosa y vanguardista, incluso pretende reducir al máximo la brecha que separa la ciencia, del derecho y la ley, pues incluye disposiciones que ahora están siendo investigadas a consecuencia del PGH (que hoy se está desarro-

15 Blázquez Ruiz, Javier, Derechos humanos y Proyecto Genoma, Granada, Comares, 1999.

16 Sobre la aplicación del instrumento, los Estados se encargan de adoptar las medidas legislativas o administrativas para poner en práctica los principios, procurando concertar acuerdos bilaterales y multilaterales para que los países en desarrollo generen su capacidad necesaria para participar en la creación e intercambio del saber científico. Con esta declaración, la UNESCO nuevamente se enfrentó al reto de crear un nuevo instrumento relativo a las ciencias de la vida. 
llando con el poco conocido Proyecto Proteoma Humano) ${ }^{17}$ y sobre la conservación de los datos genéticos y proteómicos que se generen en el futuro cercano. En este tono, la declaración de los datos genéticos es sin duda el complemento de la declaración del genoma en la defensa de los derechos humanos ante las investigaciones relacionadas con el genoma y proteoma humanos.

\section{La Declaración Universal sobre Bioética y Derechos Humanos de 2005}

A pesar de que los trabajos de la UNESCO sobre bioética datan de décadas atrás, se dio el paso decisivo con la preparación de la declaración del genoma humano y su subsiguiente adopción, es decir que de un instrumento internacional específico sobre un tema bioético y del éxito del propio documento a nivel internacional se contribuyó efectivamente a la formulación de un gran número de principios fundamentales de bioética. En las discusiones preparatorias a la nueva declaración se buscaba resolver la dicotomía entre moral y derecho. ${ }^{18}$ En efecto, moralidad y normas jurídicas corresponden a dos orientaciones distintas pero entrelazadas. Las normas jurídicas, se decía, no pueden pretender abarcar todos

17 En abril del 2001, nació oficialmente el Proyecto Proteoma Humano (PPH), coincidente con la primera reunión internacional que se celebró para presentar la Organización del Proteoma Humano, conocida por sus siglas en inglés como HUPO, institución creada para coordinar y estimular todos los estudios proteómicos que se pretenden integrar dentro del proyecto que van desde desarrollos de complejas tecnologías analíticas, construcción de bancos de datos de las expresiones proteicas, integración de datos genómicos y proteómicos, hasta ciertas aplicaciones clínicas como las posibilidades proteómicas en la clasificación de las enfermedades y en el desarrollo de medicamentos. Para más información, véase www.hupo.org.

18 La bioética, que surge a principios de los setenta, incluye una ética médica capaz de dar respuesta a las exigencias derivadas de las nuevas actitudes sociales hacia la salud, la vida y la muerte, frente a cuestiones como la relación médico-paciente, el diagnóstico prenatal, las técnicas de reproducción asistida, la ingeniería genética, el aborto, la eutanasia, y también la relación con los animales y el medio ambiente. La bioética, indispensable para enfrentar el amplísimo horizonte de posibilidades que ofrecen los adelantos científicos, da sentido a la libertad de conciencia de las personas. En la construcción de perspectivas bioéticas, han confluido la filosofía, la medicina, la antropología, la teología, el derecho, la economía, la política y la psicología (consultar el artículo de Lamas, Marta, "Debate bioético", Proceso Análisis, México, núm. 1589, 15 de abril de 2007, pp. 64 y 65). 
los campos y casos bioéticos, ni juzgar o interferir en cada momento de nuestras vidas. En otras palabras, el objetivo debería ser maximizar la evolución moral y reducir al mínimo la necesidad de la legislación nacional e internacional. ${ }^{19}$

Otra de las dificultades fue establecer la amplitud del ámbito que abarcaría el instrumento. El debate bioético cubriría dos temas entrelazados: los valores morales que actualmente guían el comportamiento de los individuos y comunidades y los valores morales y prioridades que deben guiar las políticas públicas en varios niveles sobre estos temas y los tópicos a los que debería referirse el instrumento. Igualmente, la declaración debería reunir tres requisitos fundamentales, a saber, ser sucinta, pluralista y evolutiva. ${ }^{20}$ Llama la atención este requisito evolutivo, es decir, que debería permitir considerar el carácter no obligatorio de tal instrumento, preparando al mismo tiempo su futura aplicación por la instauración de un mecanismo de seguimiento, incluyendo una función prospectiva. Con este argumento, teniendo como antecedente las anteriores declaraciones de 1997 y 2003, se decidió que el nuevo documento fuera declarativo en virtud de que los rápidos avances científico-tecnológicos requieren ser tratados con cierta provisionalidad.

Con estas pautas, después de años de trabajos en la UNESCO, se adoptó la Declaración Universal sobre Bioética y Derechos Humanos, el 19 de octubre de 2005. Cuenta con un preámbulo, 28 artículos agrupados en cinco secciones sobre disposiciones generales, principios, aplicación de los principios, promoción de la declaración y disposiciones finales. La declaración versa sobre cuestiones éticas relacionadas con la medicina, ciencias de la vida y tecnologías conexas teniendo en cuenta las dimensiones sociales, jurídicas y ambientales. ${ }^{21} \mathrm{Va}$ principalmente dirigida a los Estados pero cuando proceda también va dirigida a los individuos, grupos, comunidades, instituciones y empresas públicas y privadas.

19 UNESCO, Draft Report On The Possibility Of Elaborating A Universal Instrument On Bioethics, SHS/EST/02/CIB-9/5 (Rev2), París, 2 de mayo de 2003, trad. libre, p. 10.

20 Propuesta del Comité de Ética Francés respecto de la declaración de bioética. Véase Delmas-Marty, Mireille, "Vers une déclaration relative à des normes universelles en matière bioéthique", en UNESCO, Towards a Declaration on Universal Norms on Bioethics. Contributions Écrites / Written Contributions. SHS/EST/04/CIB-EXTR/INF 1, París, 25 de abril de 2005, trad. libre, pp. 87-91.

21 Díaz-Müller, Luis T., Bioética, salud y derechos humanos, México, Porrúa, 2001. 
Como la declaración del genoma había tenido éxito, y sus principios habían sido aceptados y en muchos países incorporados con eficacia, la declarativa bioética los retomó para ser aplicables a otros temas bioéticos específicos y no sólo a los temas derivados del genoma humano. De hecho, más que unificar ha tratado de armonizar las legislaciones para lograr consensos y que posteriormente siga el camino de la primera declaración universal, es decir que la Asamblea General de la ONU la haga suya por unanimidad. ${ }^{22}$

\section{El genoma humano en el ámbito de la Organización Mundial de la Salud (OMS)}

La OMS es un organismo especializado de la ONU creado en 1948 para que todas las personas pudieran gozar de la mejor atención en salud alrededor del mundo. Actualmente, cuenta con 192 Estados miembros. En un primer acercamiento al tema del genoma humano, se suele pensar que la OMS por su naturaleza y su mandato de protección de la salud es el organismo especializado que más ha trabajado en esta materia pero no es así; si bien no ha hecho propuestas de declaración relativas al genoma humano, sí ha emitido resoluciones y ha realizado estudios como parte de su participación en el tratamiento del tema. En el ámbito bioético se remite a los postulados realizados por la UNESCO y otras organizaciones como la Asociación Médica Mundial retomándolos y reafirmándolos. De hecho, su papel fundamental en el tema genómico es reducir las desigualdades en la investigación sanitaria mejorando las tecnologías disponibles generadas por el PGH para hacer frente a las enfermedades que

22 Romeo Casabona, Carlos María, Del gen al derecho, Bogotá, Universidad Externado de Colombia, Centro de Estudios sobre Genética y Derecho, 1996. Es por esa razón que en su redacción se prescinde de los temas más conflictivos, para que la comunidad internacional pudiera contar cuanto antes con principios aceptables en el campo de la bioética, y servir de modelo o guía para discutir y tratar de dar respuesta a un número elevado de asuntos fundamentales que aún permanecen sin resolverse. La declaración se propone ser compatible con las legislaciones nacionales, y en cierta medida encuentra limitado su alcance, dada la diversidad de puntos de vista que existe en la comunidad internacional acerca de la bioética, pero el instrumento podrá tener vocación supranacional al inspirar a futuros convenios internacionales, si no a unificar, al menos sí a armonizar las prácticas actuales. 
aquejan al mundo, pero principalmente a las que afectan a las comunidades más pobres. ${ }^{23}$

Fue la OMS la primera institución en acordar una distinción entre la clonación con fines reproductivos y de la clonación con fines no reproductivos o terapéutica. Respecto de la clonación humana con fines reproductivos la define como "el uso del genoma de un individuo para crear otro individuo genéticamente casi idéntico mediante transferencia nuclear o celular". ${ }^{24}$ No se dedica a revisar propiamente los aspectos legales, sin embargo, sí registra los países que han prohibido cualquier tipo de investigación respecto de la clonación de embriones humanos, pero en otras regiones incluso se cree que la clonación es una intervención de alta tecnología de escaso interés para las necesidades sanitarias de la mayoría de la población como sucede en la región del África negra. La OMS ha planteado algunos aspectos claves que debe contemplar la bioética para un futuro próximo tales como el relativo al uso de células madre embrionarias, un tema en el que aún no hay un acuerdo internacional; también ha adoptado un papel mundial relevante usando su poder de convocatoria en el desarrollo de códigos bioéticos internacionales y la posterior promoción de los principios. ${ }^{25}$

\section{El genoma humano en la estructura orgánica central de las Naciones Unidas}

Los trabajos en materia de bioética y los derechos humanos habían iniciado dentro de la ONU a través de las acciones y programas realizados por la UNESCO, empero, es necesario destacar que otros órganos del sistema también se interesaron en los temas bioéticos, así pues, la Comisión de Derechos Humanos de Naciones Unidas (CDHNU) a través de la Resolución 1993/91 del 10 de marzo de 1993, la primera sobre los dere-

23 OMS, Alocución de la Directora General ante el Consejo Ejecutivo en su 109a. Reunión, Ginebra, EB109/2, 109a. reunión, 14 de enero de 2002, p. 9.

24 OMS, Aplicación de resoluciones y decisiones. Repercusiones éticas, científicas y sociales de la clonación en la salud humana, 101a. Reunión del Consejo Ejecutivo, EB101/INF.DOC./3, 14 de enero de 1998, p. 5.

25 Propugna además porque todos los Estados miembros establezcan marcos reguladores para supervisar y controlar el uso comercial y médico de la genómica, atendiendo al interés público. A partir de 2003, ha promovido ante los gobiernos iniciativas para que éstos promulguen una legislación que proporcione garantías ante el riesgo evidente de utilizar la información genética para identificar una condición preexistente. 
chos humanos y la bioética, recalca los principios de ética médica relativos a la salud personal y su intima relación con la Resolución 1991/45 de marzo de 1991 relativa al desarrollo científico y tecnológico y la promoción de los derechos humanos y las libertades fundamentales. La Comisión encontró que el desarrollo de las ciencias de la vida podía repercutir en el menoscabo de los derechos humanos.

En 1995 a través de la Resolución 1995/82, solicita que los gobiernos y los organismos especializados de la ONU informen acerca de las medidas legislativas solicitadas a los gobiernos y a los organismos especializados y además se invita a que los Estados comuniquen al secretario general las medidas legislativas que se hayan tomado en ese sentido, incluida la creación de organismos o instituciones consultivas nacionales. Más tarde, a través de la Resolución 1997/71, por primera vez toma conciencia del relevante tema del genoma humano con el fin de que sus aplicaciones sean para el mejoramiento de la salud de las personas y de la humanidad, salvaguardando los derechos humanos y la necesidad de proteger la confidencialidad de los datos genéticos, por lo que juzgó necesario que los gobiernos tomasen las medidas en la creación de comités de ética nacionales en cooperación con el Comité Internacional de Bioética de la UNESCO. ${ }^{26}$

Por su parte, la Asamblea General de NU aprobó el 9 de diciembre de 1998 la Resolución A/Res/53/153 "El genoma humano y los derechos humanos", en donde se reconoce la dignidad intrínseca y los derechos iguales e inalienables de todos los miembros de la familia humana teniendo en consideración la evolución de las ciencias de la vida y los problemas éticos que plantean las aplicaciones de éstas en el ser humano, sus derechos y libertades fundamentales. La resolución acepta que el progreso científico de la genética es inevitable, pero debe prevalecer el respeto de los derechos humanos resaltando la necesidad de que la cooperación internacional sea un principio fundamental de la organización y que éste sirva para que la humanidad se beneficie de los avances de las ciencias de la vida y sus aplicaciones. Por este instrumento la Asamblea General hace suya la Declaración Universal del Genoma Humano de 1997 y resalta la importancia del seguimiento de la aplicación de la misma y la ne-

26 Cano Valle, Fernando (coord.), Clonación humana, México, UNAM, Instituto de Investigaciones Jurídicas, 2003. 
cesidad de abundar en temas relativos a la bioética tanto en los niveles nacionales como internacional. ${ }^{27}$

\section{El genoma humano en la perspectiva del Consejo de Europa}

El Consejo de Europa (COE) con sede en Estrasburgo, Francia, fue creado en 1949 y en su momento concebido para asegurar la paz y la cooperación política en los países europeos; es diferente a la Unión Europea y actualmente lo integran 46 países miembros de este continente y cinco Estados con calidad de observadores (México, Canadá, EUA, Japón y la Santa Sede). No sólo ha sido un foro de discusión sobre la identidad europea y la democracia en Europa, desde 1993 durante la Cumbre de Viena, se erigió en el "el guardián de la seguridad democrática cimentada en los derechos humanos, la democracia y el Estado de derecho". ${ }^{28}$ En la defensa de los derechos humanos, ha trabajado sobre cuatro ejes principales: el establecimiento de sistemas eficaces de control y protección de los derechos y libertades fundamentales; la identificación de las nuevas amenazas contra los derechos humanos y contra la dignidad humana; la sensibilización del público sobre la importancia de los derechos humanos; y la promoción de la educación y de la formación profesional en materia de derechos humanos. Es un contribuyente esencial del derecho comunitario europeo y algunos de sus logros han sido la adop-

27 En lo que toca al Consejo Económico y Social (Ecosoc), en su 40a. sesión plenaria de julio de 2001 aprobó la decisión 2001/273 de la CDHNU, para establecer un grupo de trabajo de expertos independientes procedentes de la UNESCO y de la Organización Mundial de la Propiedad Intelectual (OMPI) encargado de estudiar el tema. Con base en la misma resolución 2001/71 se recibieron respuestas de algunos gobiernos y organismos especializados de la ONU, tocándole a la Oficina del Alto Comisionado de las Naciones Unidas iniciar una consulta de expertos de alto nivel sobre derechos humanos y bioética para debatir la aplicación de la Declaración de UNESCO de 1997. El 15 de agosto de 2001, a través de la decisión 2001/113, el Ecosoc resolvió encargar la preparación de un documento de trabajo acerca de dicha declaración como parte de la contribución del órgano al estudio iniciado por el Comité Internacional de Bioética. Dicho documento, dado a conocer el 15 de agosto de 2002, es de especial relevancia como evaluación de todos los trabajos realizados dentro de las Naciones Unidas en diversos campos de estudio del genoma humano y la bioética, y habrá de tener especial influencia en las declaraciones y acuerdos internacionales de años posteriores. Lo cierto es que el tema ya forma parte importante de la agenda 2007-2009 de la Comisión de Derecho Internacional (CDI) de la ONU.

28 En http://www.coe.int. 
ción de 198 convenios y tratados regionales con fuerza legal, muchos de los cuales están abiertos a la suscripción de los Estados no miembros. Entre los acuerdos más importantes en materia de derechos humanos figuran el Convenio Europeo de Derechos Humanos, la Carta Social Europea, el Convenio Europeo para la Prevención de la Tortura y de las Penas o Tratos Inhumanos o Degradantes, el Convenio Marco para la Protección de las Minorías Nacionales y la Convención Europea sobre los Derechos Humanos y la Biomedicina. Por la relación directa de esta última con nuestro tema principal a continuación presentaremos un breve resumen actualizado.

Es considerada como uno de los pasos más importantes a nivel internacional en la regulación de la materia, y un documento de gran alcance ineludible de conocer y analizar. ${ }^{29}$ Fue abierto a la firma el 4 de abril de 1997 en Oviedo, España, y su entrada en vigor fue a la quinta ratificación del instrumento, hecho que aconteció el 1o. de diciembre de 1999. $\mathrm{Su}$ nombre completo es Convenio para la Protección de los Derechos Humanos y la Dignidad del Ser Humano con respecto a las Aplicaciones de la Biología y la Medicina, también conocido como Convenio de Bioética, Convenio de Asturias sobre Bioética o Convenio de Oviedo. ${ }^{30}$ Está estructurado con un preámbulo, 38 artículos contenidos en 14 capítulos. Para el tema que nos ocupa el capítulo IV sobre genoma humano resulta esencial.

Por ejemplo, estipula que las intervenciones sobre el genoma humano solamente podrán efectuarse cuando se tenga por objeto modificarlo por razones preventivas, diagnósticas o terapéuticas y sólo cuando no tenga por finalidad la introducción de una modificación en el genoma de la descendencia (principio de "no modificación del patrimonio genético

29 Romeo Casabona, Carlos María, Genética y derecho, Madrid, Consejo General del Poder Judicial, 2001, p. 303.

30 Fue firmado por 21 países miembros del Consejo de Europa, con la ausencia de Alemania y Reino Unido. Desde los preparativos del instrumento fue conocido como "Convenio de Bioética", sin embargo, durante las discusiones sobre la elaboración del instrumento internacional, algunos críticos señalaron el problema de utilizar el término "bioética", pues éste presentaba ambigüedad. Los argumentos se basaron en establecer una diferencia entre la disciplina bioética y el derecho, así que se consideró necesario aludir a un documento de carácter legal, y no a un documento en sentido estricto bioético; desde luego las normas jurídicas establecidas en el instrumento estarían basadas en los principios bioéticos reconocidos internacionalmente. 
de la humanidad"). Relativo al debatido tema de las investigaciones con embriones humanos, se previó establecer la prohibición de constituir embriones humanos con fines de experimentación, lo que ocasionó oposición directa de los científicos que lo consideraron un freno a la investigación.

Dada su naturaleza jurídica de instrumento internacional sobre materia especial, el Convenio de Bioética presenta un problema mayor respecto de la interpretación de sus disposiciones, la cual dependerá de cada país de acuerdo a la postura que adopte; para ello, el COE establece que el Tribunal Europeo de Derechos Humanos podrá emitir dictámenes consultivos, con independencia de todo litigio concreto que se desarrolle ante un órgano jurisdiccional, sobre cuestiones jurídicas relativas a la interpretación del Convenio, a solicitud del gobierno de una de las partes, mediante decisión adoptada por mayoría de dos tercios de los votos emitidos. Cabe advertir que el Tribunal Europeo de Derechos Humanos no interpretará desde el punto de vista bioético, sino jurídico las disposiciones del Convenio, amén de que su labor será sólo interpretativa y no jurisdiccional. ${ }^{31}$

De igual manera preceptúa como una de las obligaciones de los Estados miembros entregar informes acerca del modo en que su legislación interna garantiza la aplicación efectiva de todas las disposiciones del Convenio, lo que implica una adaptación de las disposiciones del instrumento al derecho interno de cada Estado. Se puede apreciar que se trata de un convenio marco, en donde cada uno de los principios enunciados se desarrollará a través de protocolos sobre materias específicas. Para poder firmar o ratificar un protocolo, el Estado debe haber firmado o ratificado el Convenio o hacerlo simultáneamente. El Convenio de Bioética quedó no sólo abierto a la firma y ratificación de países miembros del $\mathrm{COE}$, sino que se estableció que cualquier país podría hacerlo, con el fin de que el instrumento tuviera un alcance más allá de lo regional. ${ }^{32}$

31 Sagols, Lizbeth, Genética y jurisprudencia en Europa, Barcelona, Cuadernos Universidad, 2003.

32 En 2006, el Convenio de Bioética cuenta con 19 ratificaciones, es decir, que ni siquiera la mitad de los Estados miembros del COE ha decido ratificar tan importante acuerdo de voluntades. Ello refleja la discrepancia de opiniones dentro del continente europeo respecto de temas tan complejos como la bioética, y a la vez evidencia la unidad de criterios frente a ramas específicas de la biomedicina. Gómez-Heras, José, Bioética, Madrid, Alianza, 2003. 


\section{EL GENOMA HUMANO EN EL ÁMBITO DE LAS ORGANIZACIONES NO GUBERNAMENTALES Y LAS DECLARACIONES INTERNACIONALES}

Las organizaciones no gubernamentales (ONG) constituyen un fenómeno relativamente nuevo. Son definidas como "todo grupo, asociación o movimiento constituido de forma duradera por particulares pertenecientes a diferentes países con la finalidad de alcanzar objetivos no lucrativos", ${ }^{33}$ y que dentro de la teoría social de las relaciones internacionales suelen denominarse como actores trasnacionales. A continuación haremos breve referencia a las ONG que actualmente destacan a nivel mundial en el campo del desarrollo del genoma humano y la bioética, y que se han establecido como agentes muy influyentes en los esfuerzos de la comunidad internacional para elaborar un orden normativo internacional de observancia general en la materia.

\section{La Asociación Médica Mundial (AMM)}

Es una organización no gubernamental que representa a los médicos a nivel internacional. Fue creada el 18 de septiembre de 1947, cuando médicos de 27 países diferentes se reunieron en la Primera Asamblea General de la Asociación que se celebró en París, Francia. Al tener relaciones oficiales con la OMS de la ONU y al estar vinculada con otras asociaciones profesionales de salud, OIG y ONG, ha servido de foro de comunicación y debate de los problemas que enfrenta la medicina en relación con los avances científico-tecnológicos, logrando consensos sobre la ética médica, la competencia profesional y la promoción de la libertad profesional de los médicos. Sus diversas declaraciones y resoluciones han sido consideradas en el debate internacional y nacional en temas relativos a la ética médica, educación médica, asuntos médico-sociales e incluso jurídicos, entre otros. La AMM ha elaborado algunos documentos que son antecedente base de otros instrumentos internacionales relativos al genoma humano y los derechos humanos proclamados por OIG, e igualmente ha planteado algunos documentos específicos del tema desde una perspectiva médica-especializada, que han influido en la legislación

33 Marcel, Merle, Sociología de las relaciones internacionales, Madrid, Alianza Editorial, 1978, p. 338. 
nacional, regional e internacional, así como en la elaboración de códigos de conducta ética para los médicos e investigadores involucrados en la biomedicina.

Un ejemplo muy importante de esta labor de la AMM es la Declaración de Helsinki de 1964, misma que ha sido enmendada varias veces. Constituye una de las referencias ineludibles en el estudio y tratamiento del tema del genoma humano y tuvo por fin establecer una guía ética en la actuación médica, así como en la conducta ética que deben ejercer los involucrados en las investigaciones médicas en seres humanos para que dichas prácticas sean siempre en interés y beneficio del paciente. Si bien la AMM y la Declaración de Helsinki plantean principios bioéticos aplicables a la investigación relativa al genoma humano y sus aplicaciones, los destinatarios son fundamentalmente los profesionales relacionados con la medicina quienes ven ejercidas sus labores simultáneamente en dos ámbitos, la investigación y el tratamiento. Por muchos años los principios ahí plasmados fueron una de las referencias obligadas ante los problemas bioéticos relacionados con las investigaciones en seres humanos, e incluso siguen siendo aplicables no sólo a la investigación, sino a la aplicación de conocimientos que pueden llegar a vulnerar los derechos humanos.

\section{La Organización del Genoma Humano}

La Organización del Genoma Humano mejor conocida por sus siglas en inglés HUGO - Human Genome Organization-, tiene por meta coordinar los esfuerzos en la investigación del genoma humano y sus miembros activos incluyen a científicos especialistas en temas del genoma, consejeros científicos de las compañías de biotecnología involucradas en la investigación del genoma y a representantes de las agencias estatales implicadas en ella. En 1990 había crecido hasta involucrar a alrededor de 350 científicos de más de 23 países. Inició sus actividades aconsejando a los gobiernos sobre el financiamiento de la investigación en torno al genoma humano, sin embargo, para 1990 y en colaboración con los Institutos Nacionales de Salud, el Centro Nacional de Investigación del Genoma Humano y el Departamento de Energía de EUA, se inició un proyecto paralelo al $\mathrm{PGH}$, el cual sería denominado proyecto ELSI por sus siglas en inglés que significan Ethical, Legal and Social Implications, dirigido a estudiar y evaluar las implicaciones éticas, lega- 
les y sociales del PGH. ELSI desarrolló cinco metas y sus objetivos fueron diseñados para acentuar la investigación en los temas en que se requería atención adicional. Dentro del mismo PGH y ELSI, se creó un Comité Ético que debía adherirse a las normas del derecho internacional de los derechos humanos, realizando una serie de importantes recomendaciones que dieron lugar a que posteriormente se formularan diversas declaraciones y documentos en torno a la temática y que a continuación analizaremos escuetamente. ${ }^{34}$

En primer término, encontramos la Declaración sobre los Principios que rigen la Conducta en las Investigaciones Genéticas, aprobada por el Consejo Ético de la organización el 21 de marzo de 1996 y la cual parte del supuesto que la investigación relativa al genoma humano en ocasiones se contrapone a los derechos humanos, por lo que son necesarias guías éticas que acompañen en el camino a seguir. La investigación no sólo debe ser guiada por los principios de utilidad y eficiencia, si bien forman parte de los requisitos que deben poseer las guías no deben primar por encima de los derechos humanos. Segundo, aparece la Declaración sobre Muestras de ADN, adoptada en 1998 por la HUGO y que plantea varios dilemas éticos sobre la recolección de muestras de ADN en las investigaciones genéticas. ${ }^{35}$ En ocasiones los investigadores recogían el material genético sin siquiera detenerse a pensar en la posible vulneración de los derechos humanos, de ahí que el instrumento llegue a establecer varias recomendaciones importantes.

Tercero, se aprueba por el Comité Ético de la HUGO la conocida Declaración sobre Clonación, en marzo de 1999. Ya en algunos países se habían adoptado disposiciones relativas a la clonación pero muchas de ellas variaban de lugar en lugar debido a las diferentes concepciones. ${ }^{36}$ De ahí que con esta preocupación y la intención de armonizar las

34 Véase Shuster, Evelyne, "Genetic Determinism, Reductionism and Discrimination: Tightening the Chain because of the Human Genome Sequence", en Muñoz de Alba Medrano, Marcia (coord.), op. cit., trad. libre, pp. 31-33.

35 HUGO, Statement on DNA Sampling: Control and Access, Official Document, 1998, trad. libre, p. 2.

36 Tenemos, por ejemplo, a países como Eslovaquia, que ya poseía legislación relativa a la clonación humana desde 1994, o bien España, cuya Ley 35/1988, relativa a la reproducción con asistencia médica (capítulo VI, artículo 20), estipula que la creación de seres humanos idénticos por clonación o cualquier otra tecnología con fines de selección racial, atenta gravemente contra los derechos humanos, y es viable de sanciones penales. 
leyes y reglamentos de los diferentes sistemas jurídicos el Comité de Ética a través de la Declaración procedió a fijar ciertos principios cuya función sería la de ser una guía para que estas investigaciones siguieran conductas acordes a los derechos humanos. El documento propiamente versa sobre la clonación en general y no específicamente sobre la clonación humana, sin embargo, fue uno de los primeros en tratar el tema y proponer algunas orientaciones. ${ }^{37}$ En síntesis, si bien el instrumento es de los primeros que aborda internacionalmente el tema de la clonación y hace una diferencia somera entre la clonación terapéutica y la reproductiva, no realiza argumentos a favor o en contra de cada una, ni fija una verdadera postura en el tema. Es decir, más allá de proclamar principios en la materia sólo se circunscribe a señalar el estado actual de la ciencia en el tópico y sólo en algunos puntos en donde es posible establecer propuestas para legislar se limita a indicar que la prohibición o permisión de dichas prácticas es competencia y arbitrio de cada sociedad y país, con ello desecha el fin primordial de la declaración, a saber, la de armonizar las disposiciones de los distintos Estados con la aceptación de un solo instrumento internacional.

En cuarto lugar, la HUGO elaboró la Declaración sobre el Patentamiento de Secuencias de ADN que fue adoptada en abril de 2000, la cual constituye una respuesta a la Directiva Europea de Biotecnología cuya resolución 98/44/EC del 6 de julio de 1998 del Parlamento Europeo y del Consejo sobre Protección de Invenciones Biológicas de la Unión Europea contradecía la postura de la HUGO, es decir, la opuesta al argumento de que la patentabilidad del genoma impide que la comunidad científica mundial pueda tener acceso libre de la información genética. En este sentido, en abril de 2000 el Comité Ético de HUGO aprobó en Vancouver,

El 12 de enero de 1998, el Instituto Ruso de Investigaciones sobre Genética Molecular solicitó una ley que prohibiera la clonación humana. Asimismo, en Italia, por medio de un decreto del 5 de marzo de 1997, el ministro de Salud prohibió cualquier forma de experimentación y de intervención que se proponga, incluso indirectamente, una clonación humana o animal.

37 González, Toni, "La clonación terapéutica debe ser un tema de Estado y no de los partidos políticos", Barcelona 13 de septiembre de 2000, en www.diariomedico.com. Respecto a la clonación de embriones con fines reproductivos, 187 países de la HUGO han reconocido la prohibición de modo unánime. Actualmente, se ha establecido que los comités de bioética, donde hay representantes de la sociedad, de los beneficiados por los procedimientos clínicos, y de la propia comunidad científica, deben participar en cualquier legislación que se articule a nivel estatal sobre clonación. 
Canadá, la Declaración sobre la Distribución de Beneficios, con el fin de reconocer que el genoma humano es herencia común de la humanidad y la adhesión a las normas internacionales de derechos humanos. ${ }^{38}$

\section{El Consejo de Organizaciones Internacionales de Ciencias Médicas (CIOMS)}

El CIOMS es una organización internacional no gubernamental establecida en 1949 de manera conjunta por la OMS y la UNESCO. Representa en esencia a la comunidad científica que trabaja principalmente en el área biomédica. Para junio de 2007 incluía alrededor de 50 organizaciones internacionales concernientes a las disciplinas biomédicas y alrededor de 18 miembros de academias nacionales de ciencias y consejos de investigaciones médicas. Sus objetivos consisten en facilitar y promover a nivel mundial las actividades relacionadas con las ciencias médicas con la participación de las asociaciones internacionales e instituciones nacionales. En materia de genoma humano cabe destacar a guisa de ejemplo dos iniciativas básicas que pasamos a describir de modo llano.

\section{A. Pautas éticas internacionales para la investigación biomédica en seres humanos}

Ante los avances biotecnológicos, la práctica médica se coloca en constante confrontación con la sociedad debido a los dilemas éticos que esto representa, razón por la que el CIOMS estableció en 1982 esta guía ética, desarrollada con la colaboración de la OMS con el fin de que los principios enunciados por la AMM pudieran ser aplicados de manera efectiva considerando la situación concreta de cada país. El documento estuvo en constante revisión nutriéndose con las aportaciones de numerosas organizaciones internacionales, pero sobre todo, con los rápidos avances científico-tecnológicos, nuevas investigaciones, y una serie de experimentaciones hechas en poblaciones vulnerables. A fines de los noventa surgieron nuevas pautas que fueron sometidas a una consulta in-

38 Empero, los dos instrumentos dejan sin respuesta cuestionamientos sobre varios aspectos de especial importancia tales como los derechos de los investigadores sobre sus bancos de datos genéticos y los derechos del donador del tejido. 
ternacional, que se llevó a cabo en 2000 en Ginebra, Suiza. ${ }^{39}$ Así, en 2002 se llega a un nuevo texto que sustituye a todos los anteriores, con el espíritu de orientar especialmente a los países de escasos recursos, en la definición de pautas nacionales sobre ética de la investigación biomédica, aplicando estándares éticos en condiciones locales, y estableciendo o redefiniendo mecanismos adecuados para la evaluación ética de la investigación en seres humanos. ${ }^{40}$

\section{B. La Declaración de Inuyama sobre secuenciación del genoma humano, investigación genética y terapia génica}

La Declaración de Inuyama, Japón, de julio de 1990, es uno de los primeros instrumentos internacionales que hace referencia explícita a los dilemas éticos que plantea la terapia génica, aunque en general sólo establece principios éticos sobre la investigación genética y el genoma humano, a saber, la protección de la confidencialidad, el principio del consentimiento informado y de beneficencia. No aborda en el fondo el tema del genoma humano, se limita a prever y establecer las preocupaciones que despertaba en ese momento y trata de proporcionar algunas respuestas, pero no fue más allá de eso, sin embargo, su mérito es ser una de las iniciativas pioneras en la materia. ${ }^{41}$

39 Adorno, Roberto, "La dignidad humana como noción clave en la Declaración de la UNESCO sobre el genoma humano", Revista de Derecho y Genoma Humano, Bilbao, núm. 14, enero-junio de 2001, pp. 41-53.

40 CIOMS, Pautas Éticas Internacionales para la Investigación Biomédica en Seres Humanos, Ginebra, 2002, edición en español. Véase www.cioms.ch. Finalmente, en 2003 se publicó la versión del documento en español con el nombre de: "Pautas éticas internacionales para la investigación biomédica en seres humanos". Consiste de un preámbulo y 21 pautas o guías éticas, mismas que reflejan la preocupación, porque los principios éticos establecidos en la Declaración de Helsinki sean aplicados en todos los países del sistema internacional, pero con especial atención en los países en desarrollo, ya que éstos reflejan las condiciones y las necesidades de la investigación biomédica y las implicaciones de la investigación multinacional o transnacional en que ellos podrían ser partícipes.

41 Se recomienda consultar a Cely Galindo, Gilberto, La bioética en la sociedad del conocimiento, 3R Editores, 1999 y a Díaz-Müller, Luis T., Bioética, salud y derechos humanos, México, Porrúa, 2001. 


\section{EVOLUCIÓN DEL ORDENAMIENTO JURÍDICO DEL GENOMA HUMANO EN MÉXICO Y EL PAPEL DE LAS INSTITUCIONES INTERNAS E INTERNACIONALES}

México no es ajeno a la problemática que presenta el uso del conocimiento del genoma humano, pero dada la falta de infraestructura en el país, no le fue posible participar dentro del Proyecto Genoma Humano (PGH), sin embargo, algunas instituciones nacionales promovieron el análisis de las repercusiones científicas, éticas, sociales y legales que éste representa. La no intervención de México en el proyecto no hizo que el país fuera ajeno a los acontecimientos que sucedían y a través de las instituciones internas se inició un análisis respecto a las posibles implicaciones que traería el conocimiento del genoma humano no sólo en nuestro país, sino internacionalmente; los cambios que se fueron gestando a lo largo de estos años hicieron que el Estado mexicano se concentrara en tratar de iniciar un debate bioético al interior y verlo reflejado con claridad en la legislación nacional.

\section{Aspectos relevantes de la participación actual de México en el Sistema de las Naciones Unidas}

México ha tenido presencia importante, aunque a veces poco consistente, en los organismos especializados de la ONU donde ha participado para el tratamiento y discusión de múltiples rubros bioéticos como el del genoma humano y temas conexos. Como miembro de la UNESCO actuó en las discusiones parlamentarias sobre el genoma humano que se gestaron en el CIB desde su creación, donde mostró interés y preocupación por el avance biotecnológico surgido de la línea de investigación específica de la genómica y los derechos humanos en la década de los noventas. A partir de ese momento el gobierno del Estado realizó varios coloquios especializados en los que participaron varios expertos internacionales, además de reconocer la necesidad de llevar a cabo una amplia reforma de la legislación nacional en lo relativo a las investigaciones sobre el genoma humano, tomando conciencia que dicha modificación del marco jurídico mexicano debía velar por la dignidad del individuo frente al manejo de la información genética. 
La misma preocupación planteada por México en la UNESCO, fue manifestada en la Oficina Panamericana de la Salud. ${ }^{42}$ Con el establecimiento del CIB, la UNESCO instó a sus Estados miembros a crear organismos consultivos en el área bioética, por lo que México procede a crear una instancia consultiva pluridisciplinaria para brindar asesoramiento sobre las cuestiones relativas a la bioética y estudiar las cuestiones relativas a investigación genética; nace así la Comisión Nacional de Bioética, un comité nacional consultivo sobre derechos, salud y bioética encargado de evaluar los temas bioéticos y orientar tanto a los legisladores como a las instancias judiciales y a las autoridades gubernamentales sobre los diversos temas que confluyen en el manejo de la tecnología genética, humana y animal. Con ello, México pasó a formar parte del Comité Internacional de Bioética. ${ }^{43}$

En otro orden de prioridades y como parte de la discusión del tema del genoma humano en la UNESCO y en la Asamblea General de la ONU, se decidió tratar el problema de la clonación humana en el seno del órgano deliberativo más importante de la organización, a través de su Sexta Comisión, en cumplimiento a la Resolución 56/93 de diciembre 12 de 2001. El gobierno mexicano no sólo fue parte activa de las negociaciones, sino que hizo una serie de propuestas relativas a la conformación del documento jurídico. El 24 de septiembre de 2002 el Representante Permanente de México ante el Grupo de Trabajo sobre Clonación de la Sexta Comisión pronunció algunos de los puntos que debían considerarse en la negociación y en la elaboración del documento internacional, en el que se reconoció que el tema de la clonación humana no podía ser abordado sin considerar complejas cuestiones científicas, éticas y jurídi-

42 OPS-OMS, Programa Regional de Bioética. Informe Anual de Actividades, Santiago de Chile, 2000, p. 5.

43 Con este impulso se creó más tarde el Instituto de Medicina Genómica, en Cuernavaca, Morelos, en cumplimiento al mandato de la OMS que instó a los Estados miembros a establecer centros e instituciones dedicados a este tipo de investigación avanzada. A partir de 2002, al interior de México se ha hecho muy necesario intensificar el diálogo interinstitucional entre las distintas dependencias del Ejecutivo federal, el sector científico y académico, y la sociedad civil, no sólo para promover la adhesión del país - como parte del TLCUEM 2000 - a los instrumentos adoptados por el Consejo de Europa en materia de biomedicina, es decir, el Convenio de Oviedo relativo a los derechos humanos y la biomedicina, y a las disposiciones de la Declaración Universal del Genoma Humano y los Derechos Humanos, sino para debatir jurídicamente e incorporar el tema en nuestra legislación positiva constitucional y reglamentaria. 
cas, ello con el fin de que la diversidad existente dentro de la organización no impidiera lograr el consenso. ${ }^{44}$

En ese momento México expresaba su respaldo a la propuesta de Alemania y Francia, pues se consideró que acordar una prohibición de la clonación humana reproductiva no impediría a los Estados miembros adoptar en sus legislaciones internas las prohibiciones en otros sentidos, incluso más estrictas o absolutas. De esta manera, para el 17 de octubre de 2002 México se pronunciaba por la intensificación de las consultas internacionales con la finalidad de llegar a un acuerdo donde se salvaguardaran los valores universales y, sobre todo, los derechos humanos consagrados como el del respeto a la integridad y a la dignidad de la persona y la no discriminación cuyas consecuencias se vislumbran de gran relevancia. ${ }^{45}$

Con este segundo discurso, sólo unos meses después de la postura inicial que apoyaba la iniciativa franco-alemana, México adopta una moratoria para que los Estados se comprometieran a prohibir todo tipo de clonación que atentara contra la dignidad humana; moratoria que estaría en vigor mientras se adoptaran y adquirieran fuerza vinculante instrumentos internacionales en la materia, lo cual significaba una primera contradicción, ya que en un principio México solamente apoyó la idea de regular la clonación humana reproductiva y dejar a la terapéutica como un tema reservado al derecho interno de cada Estado. ${ }^{46}$ Sin embargo, nuestro gobierno esperaba que para 2003 se aprobara de forma consensuada, una decisión de fondo que facilitara el inicio y conclusión de la elaboración de un instrumento internacional sobre clonación. Pasa así el tiempo y fue durante la presidencia de México en el Grupo de Trabajo cuando el gobierno de Costa Rica presentó una carta dirigida al secretario general de la ONU con un texto explicatorio de su proyecto tendiente a la prohibición de todas las formas de clonación humana; en el mismo lapso se examinó un documento presentado por la Santa Sede con los mismos objetivos de Costa Rica. Más tarde se presentaría el proyecto de Bélgica tendente a limitar la prohibición sólo al caso de la clonación

44 Motta, Lourdes, Documento de Trabajo. Clonación Humana en la Organización de las Naciones Unidas, 27 de junio 2005, p. 9.

45 Quien esto escribe, tuvo oportunidad de plantear y aclarar ahí algunos criterios que fueron finalmente considerados.

46 Velázquez Elizarrarás, Juan Carlos, Discusiones en bioética y derechos humanos, México, CNDH, 2005. 
reproductiva y a dejar a cada Estado regular los aspectos de la clonación terapéutica.

Estaba claro que sin un consenso real la convención estaría destinada al fracaso, pero se esperaba que el tiempo que transcurriera hasta el 60o. periodo de sesiones de la Asamblea General diera a los Estados la oportunidad de seguir investigando sobre los complejos problemas técnico-científicos, jurídicos y éticos vinculados a la clonación y en ese sentido, México se comprometió a apoyar las propuestas encaminadas a organizar talleres o seminarios a nivel de expertos, dentro o fuera de las Naciones Unidas, con el ánimo de seguir profundizando el conocimiento en la materia. Pero el tema fue nuevamente discutido en el 59o. periodo de sesiones y en octubre de 2004 aún no se había logrado un consenso y fue entonces cuando el gobierno mexicano decidió tomar una postura oficial dándola a conocer a través de su Cancillería en su comunicado 231 del 20 de octubre de 2004 que señala "en caso de verse obligado a emitir un voto en torno a los proyectos de resolución presentados, su decisión será a favor del proyecto de Bélgica". ${ }^{47}$

Contradiciendo el discurso de México del 6 de noviembre de 2003 y reafirmando la postura señalada en el comunicado núm. 231 de la SRE, se expresó que México estaba a favor de una convención que prohibiera de manera absoluta la clonación reproductiva y estableciera criterios para que los Estados regularan de manera pronta y eficaz otros tipos de clonación en su legislación nacional, sujetándolos a controles estrictos, o incluso prohibiéndolos; así, con base en criterios acordados internacionalmente, cada país tendría la potestad de determinar en su legislación, siguiendo sus propios procesos políticos, los límites y alcances de la clonación terapéutica. La propuesta mexicana finalmente no fue considerada, pues se decidió partir del proyecto presentado por Italia en noviembre de 2004 en donde se propone ya no una convención, sino una declaración que prohibiera todos los tipos de clonación humana. Las discusiones se extendieron hasta febrero de 2005 y se presentaron múltiples propuestas de la declaración, una por parte de Honduras, la italiana y una enmienda hecha por Bélgica al proyecto de Honduras.

47 SRE, "Posición de México sobre la Convención Internacional contra la Clonación de Seres Humanos con Fines de Reproducción", Comunicado de Prensa núm. 231, México, 20 de octubre de 2004. Véase www.sre.gob.mx. 
En ese momento, México votó a favor de la postura hondureña que pretendía prohibir todas las formas de clonación humana en la medida en que sean incompatibles con la dignidad humana y la protección de la vida humana; con ello, se consideraba que el país aceptaba la prohibición de todas las formas de clonación humana. La Asociación Mexicana de Ciencias, el Colegio de Bioética y el Foro Consultivo de Ciencia y Tecnología, ${ }^{48}$ ante el sentido del voto emitido por México en la Asamblea General publicaron un desplegado en el que pedían al gobierno reconsiderara su posición antes de emitir su voto final. Todos los firmantes, considerados como autoridades en bioética y biotecnología señalaron: "Los países que se opongan a este desarrollo quedarán marginados del progreso científico en este campo y de los extraordinarios beneficios que podrían derivarse del mismo para millones de personas". ${ }^{49}$ Finalmente, el texto que prevaleció fue el de Honduras y el 8 de marzo de 2005 fue adoptada la declaración por mayoría de votos y México fue uno de los 84 países que votó a favor de la adopción de la Declaración de las Naciones Unidas sobre la Clonación de Seres Humanos, haciendo caso omiso a las opiniones de numerosos científicos, juristas e instituciones nacionales que no estuvimos ni estamos de acuerdo con la prohibición de todas las formas de clonación humana. ${ }^{50}$ Sin embargo, en la lectura detallada del documento, la vaguedad y ambigüedad del texto parecen señalar que el destino de la reglamentación de ambas formas de clonación sería competencia de cada uno de los Estados de acuerdo con su legislación interna.

48 Juntos agrupan alrededor de cinco mil científicos.

49 Cruz, Antimio, "Freno a la ciencia: prohíbe ONU todo tipo de clonación", sección Cultura, El Universal, 9 de marzo de 2005. Véase www.eluniversal.com.mx. También Gómez- Heras, José Ma., Dignidad de la vida y manipulación genética, Madrid, Biblioteca Nueva, 2002, 301 pp.

50 La participación de México se mostró incoherente, cambió de posturas a lo largo de las negociaciones, en un principio pareció acordar con la propuesta de Alemania y Francia, y abordar el tema cuanto antes, luego se contradijo al aceptar la moratoria para analizar la posibilidad de abordar el tema de la clonación reproductiva, luego rechazó todos los tipos de clonación humana, y después de abstenerse de votar en 2004, adopta su postura oficial al inclinarse por el proyecto de Bélgica que pretendía regular sólo la clonación reproductiva, y dejar a los Estados la regulación interna de la clonación terapéutica, hecho que finalmente no respetó sino que asumió el proyecto de Honduras con sus modificaciones, aunque al parecer rechazó todos los tipos de clonación humana. 
El hecho de que México no se mantuviera coherente y constante en su postura, hizo que después de la votación del 8 de marzo de 2005, tuviera que aclarar el sentido de su voto ${ }^{51}$ y fue el primer país en pronunciarlo ante el pleno de la Asamblea General. En este sentido, la Cancillería señaló: "México se guió por la necesidad de alcanzar un consenso en un tema de interés mundial, que asegurara el respeto a la dignidad humana en la aplicación de la ciencia. Corresponderá ahora a las legislaciones nacionales precisar los alcances de la Declaración, incluyendo los términos que utiliza, de conformidad con los criterios culturales, filosóficos y religiosos que predominen en cada sociedad y el respeto de los derechos humanos reconocidos por la comunidad internacional". ${ }^{52}$ A pesar de las divisiones surgidas en el seno de la ONU, el instrumento internacional debe contribuir a la discusión nacional del tema que aún no cuenta con legislación específica al respecto. En nuestro país la disposición fue considerada por varios académicos y científicos como un freno real para la investigación de células madre embrionarias, llegándose a afirmar que el avance científico de los países que rechazaron la prohibición, como Reino Unido, Bélgica y China, va a ser a pasos agigantados, mientras que los que asintieron quedarán estancados. Empero, consideramos que siendo la declaración un documento no vinculante, no es ineludible seguir las disposiciones que ésta manifiesta, esto es, deja margen a la interpretación que haga cada país para determinar dónde se encuentran los límites de la investigación para garantizar el respeto a la dignidad de las personas. ${ }^{53}$

51 Recordemos que México no fue el único país en verse obligado a explicar el sentido de su voto, en total fueron llamadas 27 delegaciones a argumentar su postura. Este fue un ejercicio muy interesante que permitió conocer más a fondo las posiciones de los Estados en distintos momentos de una negociación complicada y extenuante.

52 SRE, "Adopta la Asamblea General de la ONU la Declaración de las Naciones Unidas sobre Clonación Humana", Comunicado de Prensa núm. 40, México, 8 de marzo de 2005. Véase www.sre.gob.mx.

53 El siguiente paso consistirá en que el Congreso de la Unión, en sus próximas legislaturas (en el periodo presidencial 2006-2012), fije los límites a la investigación en materia de clonación mediante la modificación de la ley o bien la creación de una normativa específica. La Declaración de la ONU, al no ser un instrumento vinculativo, sólo puede representar una guía, y la normativa podría adaptarse conforme a las decisiones que tome nuestro país, en función de la Constitución y de los criterios filosóficos, religiosos y culturales que adopte la legislatura que corresponda. Así que México, en aras de la construcción de una normatividad jurídica que responda a la realidad, deberá obtener información completa, clara, verdadera, y no datos falsos y fragmentados como los que han 


\section{La regulación del genoma humano en el marco de las instituciones mexicanas}

En la actualidad son varios los aspectos que deben ser abordados por las instituciones mexicanas para regular los avances científicos del genoma humano y sus aplicaciones; el gobierno de México a pesar de participar en organismos internacionales que trabajaron desde los noventa, no había creado una institución dedicada al tratamiento del rubro, sino simplemente grupos de trabajo de diferentes organismos nacionales sin una vinculación clara entre sí. Las noticias que llegaban de la comunidad científica mundial y de otros grupos a México sobre el tema del genoma humano y sus aplicaciones hicieron que en el país se abrieran distintas expectativas por su posible uso, pero a la par comenzó la preocupación por los daños que podrían causarse si los fines previstos se pervirtiesen. Instituciones como la UNAM con el Núcleo de Estudios Interdisciplinarios en Salud y Derecho del Instituto de Investigaciones Jurídicas fueron de los primeros en abordar de manera seria el tema del genoma humano $y$ el derecho. Asimismo, a partir de la reforma académica que comenzó en 1993 y culminó en 1997, en la Facultad de Ciencias Políticas y Sociales a través de su Centro de Relaciones Internacionales y el Seminario de Derecho Internacional se estableció, entre otros, el nuevo Programa del Seminario de Relaciones Jurídicas Internacionales, donde bajo la coordinación de quien suscribe y del doctor Antonio Murguía Rosete, se comenzó a estudiar de manera sistemática y bajo un enfoque multidisciplinario pautado por el derecho internacional, los derechos humanos y el derecho de la propiedad intelectual, un conjunto de temas relacionados con el genoma humano, la clonación, la eutanasia y la eugenesia, la bioética y sus regímenes legales, así como los sistemas jurídicos de protección nacional e internacional. ${ }^{54}$

proporcionado algunos de los grupos más conservadores, y que ven en este importante instrumento internacional, no una regulación modelo a estudiar e interpretar sino, por el contrario, un documento ineludible de considerar y que debe ser inserto, sin debate ni ajustes, en la legislación interna.

54 A partir de estos esfuerzos académicos, se han producido valiosas investigaciones de tesis de licenciatura y posgrado, se han organizado actos de relevancia nacional e internacional en estas materias, y se están desarrollando proyectos para el mejoramiento de la enseñanza con importantes productos literarios de amplia difusión, como el Anuario Mexicano de Derecho Internacional que el amable lector tiene ahora en sus manos. 
Más tarde, con el establecimiento de la Comisión Nacional de Bioética se dio un mayor impulso a la regulación inmediata del tema y sus elementos correlativos. Ese llamamiento de estas y otras importantes instituciones más como universidades, institutos e instancias gubernamentales, provocó que los órganos encargados de la labor legislativa y de justicia tomaran aún mayor conciencia de la importancia de analizar y regular cuanto antes el tema, dando lugar a algunos avances que muestran el estado del arte de estas disciplinas de la vida en el ámbito nacional. Nace así la Comisión Nacional para el Genoma Humano (CNGH), ${ }^{55}$ como resultado de la coordinación de esfuerzos de la Secretaría de Salud, la UNAM, el Conacyt y la Fundación Mexicana para la Salud (Funsalud), con el mandato de analizar las implicaciones del genoma humano y de esta manera coordinar las políticas y acciones de las dependencias e instituciones educativas y de salud que trabajaran en el tema. Desde sus inicios la CNGH estudió la factibilidad de establecer un centro dedicado al estudio de la genómica en donde convergieran participantes de varias instituciones, de tal suerte que en 2003 se planteó la posibilidad de crear el Instituto de Medicina Genómica (Inmegen), que fue un tema ampliamente discutido en el congreso mexicano y que finalmente culminó con su creación el 20 de julio de 2004.

El nuevo instituto tenía atribuciones que competían a la CNGH por lo que se abrogó el acuerdo de creación de la comisión del genoma, así que a partir de ese momento tanto el Inmegen como la CNB serían las instituciones encargadas de analizar los aspectos relativos al genoma humano. Un comité de bioética requiere de cierta autonomía para emitir sus opiniones y en función de ello el 7 de septiembre de 2005 se creó la Comisión Nacional de Bioética como órgano desconcentrado tendente a "promover el estudio y observancia de valores y principios éticos para el ejercicio tanto de la atención médica como de la investigación en salud". ${ }^{56}$ La CNB no está destinada únicamente a abordar aspectos relativos al genoma humano, sino que incluye temas como el aborto, la reproducción humana, y la ética ambiental, por mencionar algunos, y junto

55 "Acuerdo por el que se crea la Comisión Nacional del Genoma Humano", y "Acuerdo por el que se crea con carácter permanente la Comisión Nacional de Bioética", DOF, México, lunes 23 de octubre de 2000, pp. 72-75.

56 "Decreto por el se crea el órgano desconcentrado denominado Comisión Nacional de Bioética", DOF, miércoles 7 de septiembre de 2005, p. 91. 
con otras instituciones integrantes del consorcio promotor del Inmegen han emitido información importante para ser discutida en el ámbito nacional e internacional, como los debates que se gestaron en la Asamblea General de la ONU sobre clonación humana.

En temas nacionales, se inició en 2005 y continúa en 2007 bajo la dirección del Inmegen, un proyecto de elaboración del mapa genómico de la población mexicana en los estados de Yucatán, Zacatecas y Sonora, a los que seguirán Veracruz, Morelos y Guerrero cuyo propósito es el estudio de la variabilidad genómica de la población mexicana. ${ }^{57} \mathrm{El}$ análisis de fondo y consolidación de un mapa genómico de los mexicanos tendrá que enfrentar muchos problemas relacionados con la ética y el uso que se dará a su conocimiento en todo el país; es aquí donde la CNB entra en escena para proporcionar información a las dependencias gubernamentales interesadas, instituciones académicas, medios de comunicación y a la población en general, especialmente al Congreso de la Unión con el fin de generar desde ahora una discusión informada para que éste proceda a legislar con calidad el tema y sin mayores dilaciones.

\section{La regulación del genoma humano en el marco de la legislación del Estado mexicano}

A pesar que desde la década de 1990 inició la aventura por lograr el mapeo del genoma humano en los países industrializados y se dio el posterior arribo de noticias novedosas y sorprendentes como preocupantes a México, y a pesar de existir la inquietud por parte de algunos grupos de científicos, así como de sectores de la sociedad interesados porque el avance del derecho alcance los vertiginosos pasos de la ciencia, prácticamente no hubo respuesta o iniciativa legal alguna de los legisladores mexicanos, sino hasta principios de 2000. La CNGH hizo el primer llamado sobre la necesidad de regular el tema del genoma humano, mismo que fue escuchado por algunos legisladores, surgiendo así la iniciativa por el PRD de la Ley sobre la Investigación, el Fomento, el Desarrollo, Control y Regulación del Genoma Humano, con el objetivo principal de crear mecanismos legales para regular la investigación del genoma humano y en ese sentido estableció 10 artículos que de manera general engloban los

57 Gómez Quintero, Natalia, "Sugieren no frenar investigación genómica”, El Universal, Primera Plana, 27 de septiembre de 2005, p. 1. 
siguientes aspectos: en primer término, que el genoma humano constituye el patrimonio de la humanidad y por tanto no es patentable su conocimiento, y la investigación y los descubrimientos de éste serán considerados como estratégicos y prioritarios por el Estado; que todas las personas, sin distinción de credo, raza, sexo y posición social, deberán tener acceso a los progresos biológicos y genéticos, y a su vez estas investigaciones deberán estar orientadas a aliviar los males de la sociedad; que el Centro de Medicina Genómica y Molecular reciba los recursos económicos necesarios y sea integrado a través de una alianza entre la UNAM, la Secretaría de Salud, el Conacyt y Fuensalud; que debe prohibirse la utilización de la ingeniería genética para producir armas biológicas o de exterminio de la raza humana; y que se responsabilizará a los científicos encargados de las investigaciones de aplicar bases legales y morales, de investigar y aplicar sus investigaciones y descubrimientos apegados a derecho y acorde con los cánones de discreción, ética y moral de los seres humanos..$^{58}$

Si bien la iniciativa de ley trataba aspectos importantes para la protección del genoma humano, no contenía todos los elementos necesarios para resguardarlo, pero representó uno de los primeros pasos en la regulación del tema en México. No obstante, a pesar de haber sido aprobada por el pleno de la Cámara de Diputados y turnada al Senado, la iniciativa fue relegada a un segundo plano y hasta hoy sigue esperando ser revisada.

Más tarde surgió otra propuesta del PVEM a través de una iniciativa tendente a reformar los artículos 1o., 4o., 28 y 89 constitucionales para la protección del genoma humano mismo que fue presentado el 1o. de octubre de 2002. En la exposición de motivos del proyecto se expresa que la cuestión del genoma humano no puede dejarse a una posterior interpretación judicial, sino que debe quedar claramente establecida su protección. La información genética sólo deberá utilizarse para aumentar el respeto de la dignidad humana, efectuándose así, un llamado público a favor de un posterior debate sobre las implicaciones éticas, sociales y legales por su uso. La protección del genoma humano estaría encaminada a considerarlo como un bien público y a la par como la base genética indi-

58 Para un buen ejercicio de derecho comparado, consúltese Iglesias Prada, Juan Luis, La protección jurídica de los descubrimientos genéticos y el proyecto genoma humano, Madrid, Civitas, 1995. 
vidual cuya información es de orden privado, de tal manera que estaría garantizada la confidencialidad de la información obtenida de análisis genéticos y el derecho de saber o no si es portador de una enfermedad genética. ${ }^{59}$

En diciembre de 2001 se habían hecho intentos en este mismo sentido, en la ocasión en que el PAN presentó una iniciativa que pretendía introducir a la Ley General de Salud un capítulo décimo octavo destinado exclusivamente al tema del genoma humano en el que de manera general se planteó que: ${ }^{60}$ el genoma humano es la base de la unidad biológica fundamental de todos los miembros de la familia humana y patrimonio de la humanidad y por tanto, no puede dar lugar a beneficios pecuniarios, ni puede ser objeto de patentes, ni restricciones en la información por los mismos motivos; cada individuo tiene derecho al respeto a su dignidad y derechos, cualesquiera que sean sus características genéticas y, por tanto, nadie podrá ser objeto de ningún tipo de discriminación, ni de que se le violen derechos. Se debe asegurar la confidencialidad de los datos genéticos asociados a una persona identificable, obtenidos o conservados con fines de investigación, diagnósticos, terapéuticos o de cualquier otro fin. Finalmente, esta iniciativa fue turnada a las comisiones de Salud y de Ciencia y Tecnología quienes la modificaron y retomaron en 2003 cuando inició la labor determinante, previo estudio de legislación comparada - de Chile, España y EUA principalmente - relativa al tema y considerando los acuerdos internacionales de que México era parte, principalmente, la Declaración del Genoma Humano de la UNESCO y el Convenio de Bioética del Consejo de Europa, así como opiniones e información emitidas por el Inmegen, UNAM, Institutos Nacionales de Salud y la Academia Mexicana de Ciencias.

Después de considerar un sinnúmero de elementos de discusión, la Cámara de Diputados aprobó por 426 votos la inclusión de un título de

59 Gómez Bravo, Emilia Patricia, "Iniciativa de Ley que reforma los artículos 4o. y 28 de la Constitución Política de los Estados Unidos Mexicanos, en materia de protección al genoma humano", Gaceta Parlamentaria, núm. 64, martes 1o. de octubre de 2002, p. 3 .

60 Orozco, Manuel Wistano, "Iniciativa que reforma la Ley General de Salud, en materia de genoma humano", Gaceta Parlamentaria, 14 de diciembre de 2001, pp. 1-8. Habría que revisar la tesis de la alumna Castro Sánchez, Elizabeth, El genoma humano y los derechos humanos en el sistema internacional, México, UNAM, FCPS, 2006, pp. 349-370. 
genoma humano en la Ley General de Salud, recordando la iniciativa presentada en 2001 por el PAN y a la par surgió el proyecto de crear el Inmegen. De acuerdo al proceso legislativo establecido en la Constitución mexicana el proyecto de adición a la Ley General de Salud una vez aprobado por la cámara baja fue remitido a la cámara alta para su estudio y revisión; la minuta presentada por los diputados estableció la adición a la fracción IX bis del artículo 3o. y la adición de un título quinto bis y su capítulo único denominado "El genoma humano", así como el artículo 421 bis, de la citada ley. Los debates fueron turnados a las comisiones de Salud y Seguridad Social, de Ciencia y Tecnología y de Estudios Legislativos de la cámara alta y ahí permaneció sin avances los siguientes meses. El Senado sólo continuó su labor respecto de la creación del Inmegen lo que también le había sido turnado por los diputados, decidiendo aprobar las adiciones propuestas a la Ley de los Institutos Nacionales de Salud con lo que se posibilita su creación con base en el decreto publicado en el DOF de 20 de julio de 2004.

\section{REFLEXIONES FINALES}

No cabe duda que el derecho internacional y los derechos humanos, así como los sistemas jurídicos internos de los Estados, tienen en el genoma humano y la bioética, dos de los más grandes desafíos de los tiempos modernos, a los cuales vienen dando diferentes respuestas jurídicas y un consistente, aunque no suficiente, tratamiento político-normativo y legislativo con el apoyo de los organismos internacionales, el concurso activo de la sociedad civil internacional y la utilización sistemática del método jurídico-político de las declaraciones internacionales y los instrumentos convencionales regionales.

Los estudiosos del derecho internacional y de los derechos humanos, enfrentamos el reto de que la mayoría de los sujetos y actores ignoren aspectos básicos del régimen jurídico aplicable a la bioética y el genoma humano, los derechos y obligaciones derivados, la naturaleza jurídica del nuevo bien a tutelar, o más aún el papel que deben jugar las instituciones al interior y exterior de los Estados y la propia sociedad civil internacional en la tarea ordenadora del fenómeno en cuestión que corresponde coordinar a la ciencia jurídica. Y en este punto fino, seguirá siendo interés de las universidades y los institutos a través de los académicos e investigadores, contribuir a ampliar el criterio y a mejorar el conocimiento 
con que el juez y el legislador enfrentan la problemática genómica y bioética, porque de ello depende no sólo la calidad de las normas producidas, el contenido de las líneas rectoras y la validez y eficacia de las leyes y reglamentos, sino también la evolución de la costumbre y la correcta interpretación del derecho para obtener una jurisprudencia depurada y precisa, en los ámbitos de su aplicación interna e internacional.

Por su parte, aunque sus acciones no han sido del todo suficientes, varias organizaciones intergubernamentales, principalmente las integradas en el sistema de las Naciones Unidas, han puesto especial atención en las consecuencias que tendría el avance biotecnológico de tales proyectos como el PGH, vislumbrando las posibilidades de ciertas transgresiones a los derechos humanos. Ello explica la realización de importantes estudios, reuniones y debates así como el pronunciamiento de iniciativas clave sobre el tema genómico para plantear soluciones sociales, éticas y legales mediante la emisión de documentos, resoluciones, declaraciones $\mathrm{y}$ convenios internacionales enmarcados en el derecho internacional público y privado.

De estos esfuerzos surgió y se consolidó más tarde una metodología para la elaboración de acuerdos internacionales basada en la formulación de declaraciones concernientes a los derechos humanos. La fórmula declarativa había sido la más usada como un recurso del derecho internacional para crear conciencia en garantizar el bienestar de la humanidad a través de la observancia de los derechos fundamentales del hombre; en efecto, a pesar de crear conciencia moral, las declaraciones fueron reconocidas tanto en teoría como en la práctica con fuerza legal, como se desprende de la Declaración Universal de los Derechos Humanos cuyas disposiciones han sido introducidas en las legislaciones nacionales de numerosos países.

El instrumento declarativo ha sido hasta ahora el más eficaz para establecer las bases del derecho internacional del genoma humano, pues es lo suficientemente general y mantiene cierta flexibilidad en un tema científico en constante avance, tomando en cuenta las posiciones que obedecen a las diferencias culturales, políticas e incluso religiosas de cada país. En este sentido, la convención pasó a ser un complemento de la declaración, y no al revés, pues se consideró que el factor tiempo era de especial importancia por el progreso inevitable, y dado que el mundo necesitaba cuanto antes de la regulación internacional de la materia para proteger de esta manera la especie humana y sus derechos. Así, se 
estimó que una convención era rígida considerando que habría que hacer numerosas enmiendas al instrumento pasados algunos años y éstas requerirían de la aprobación de los Estados miembros. Será entonces la declaración la fórmula más acertada para lograr los propósitos de los futuros acuerdos internacionales y para obtener la adhesión de la comunidad internacional a los principios encaminados a fomentar la protección del genoma humano y la aplicación de la bioética, amén de que en la práctica tiene la posibilidad de ser adoptada con mayor rapidez.

En la misma dinámica, las resoluciones de organismos internacionales también han sido un contribuyente insuperable como fuente del derecho internacional del genoma humano y la bioética, principalmente las afiliadas al sistema de Naciones Unidas como la UNESCO, la OMS, el Ecosoc y la Asamblea General, sin pasar por alto el papel de los organismos regionales como la OEA y el Consejo de Europa que, en general aceptan que el progreso científico de la genética es inevitable, pero debiendo prevalecer el respeto de los derechos humanos, principalmente los de nueva generación. Y aquí también los órganos jurisdiccionales comienzan a cobrar gran relevancia; así lo hace patente el Tribunal Europeo de Derechos Humanos que ya puede emitir dictámenes consultivos, sin interpretar desde el punto de vista bioético, sino jurídico, las disposiciones del Convenio, siendo en este caso su labor solamente interpretativa y no jurisdiccional.

Destacan asimismo en esta tarea coadyuvante de la reciente evolución progresiva del derecho internacional del genoma humano, una serie de importantes organizaciones no gubernamentales como el Consejo de Organizaciones Internacionales de Ciencias Médicas (CIOMS), la Asociación Médica Mundial (AMM), una de las pioneras en plantear una normativa en el ámbito de la genética y la genómica, al igual que la Organización Internacional del Genoma Humano (HUGO), las cuales además de sus notables logros pretenden con éxito armonizar las leyes y reglamentos de los diferentes sistemas jurídicos procediendo a fijar ciertos principios cuya función es la de constituir una guía para que estas investigaciones sigan conductas acordes a los derechos humanos.

Respecto a la recepción del derecho internacional en materias de genoma humano y bioética en el sistema jurídico de México y el desarrollo jurídico-legislativo interno alcanzado, los debates generados en ambas cámaras del Congreso mexicano reflejan por un lado, el interés por regular ambas temáticas cuyo conocimiento impacta múltiples áreas, mientras 
por el otro, muestran la ignorancia político-jurídica de los señores legisladores al confundir, por ejemplo, a la clonación humana con la investigación del genoma humano, que si bien sabemos tienen relación, no son lo mismo. Lo lamentable y que habrá de corregirse ya, es que gran parte de los debates en torno a la aprobación de los proyectos de adición a un título dedicado al genoma humano en la Ley General de Salud y de la creación del Inmegen se vieron enfrascados en temas de clonación humana y de manipulación de células madre embrionarias, mismos que debieron haber sido tema de otras iniciativas, puesto que no tenían efecto al menos en la formación del Instituto, ni directamente con la protección del genoma humano.

Desafortunadamente, en este y otros problemas cuya solución reviste gran interés para la sociedad mexicana, el Congreso ha mostrado notable incapacidad, excesiva politización partidista, anquilosamiento y una preocupante falta de calidad y oficio profesional para legislar que es, no se olvide, su razón misma de ser y de actuar. Es por ello que hasta el momento de escribir estas reflexiones, el intento más cercano que tenemos en México para tratar de ordenar y regular el tema del genoma humano, y de materializar la recepción del derecho internacional en el derecho interno, no se ha dado a través de la promulgación de una ley o un reglamento, sino a través de la creación del Inmegen, una institución de la que se dictan algunas de sus atribuciones y que se refiere fundamentalmente a disposiciones relativas a la medicina genómica, quedando muchas lagunas que deben ser llenadas de fondo y sin mayor demora, más aún a la luz del papel protagónico que asume ya el país en la segunda fase del PGH a nivel mundial.

Es cierto, algunas disposiciones del sistema jurídico mexicano protegen indirectamente ciertos aspectos como el consentimiento informado, el derecho a la salud, el derecho a la privacidad, pero hoy en México el genoma humano sigue desprotegido y la bioética confundida, por lo que las personas y sus derechos humanos pueden verse seriamente afectados en ese sentido. Debemos procurar pues, acciones inmediatas para evitar que nuestro país continúe convirtiéndose en lo que de hecho ya está siendo, un verdadero paraíso genético y bioético. 